\title{
Geneticists prepare for deluge of mutant mice
}

Alison Abbott, Bar Harbor

Off-the-shelf, made-to-measure mouse models of any human disease could be available sooner than you think. Medical researchers will be able to select their perfect model from a catalogue of mutants covering every single gene, specialists say.

Researchers who run the world's biggest mouse archives met in Bar Harbor, Maine, on 19-21 November to discuss how to handle the 300,000 or so new lines of mice that could be generated over the next two decades, expanding their stocks by almost a hundredfold.

"We will be hit by the start of the deluge within five years," predicts Steve Brown, head of the Mouse Genome Centre in Harwell, UK. International consortia of mouse geneticists have already announced plans to launch the first large-scale programmes to generate mutants systematically, gene by gene (see 'It's a knockout', below).

About a dozen 'mouse resource centres' were represented at the meeting, including the Rome-based European Mouse Mutant Archive (EMMA), the Jackson Laboratory in Bar Harbor and the RIKEN BioResource Center in Tsukuba, Japan. The centres collect the mutant mice made by scientists and distribute them to other researchers on request.

At the meeting, they decided to form an alliance that will share information through a single website, avoid duplication of lines, and present a single global voice when pressing for more funding. "We have to move from being a cottage industry and open ourselves globally to an international biomedical community," says Brown.

The glut of new mouse strains is expected to follow completion of the human and mouse genomes. The best way to make sense of this information is to see what happens to a living organism when individual genes are manipulated. Mice have proven particularly easy to alter genetically, so have become the most-wanted lab species.

The mouse is reckoned to have between 22,000 and 25,000 genes, and biologists would like to have a choice of perhaps ten or more types of mutant per gene. New cryogenic technologies that allow the freezing of viable mouse sperm or embryos created by in vitro fertilization will help ensure the archives are not overburdened with live mice.

"We don't want too many cages with live animals," says EMMA chief Martin Hrabé de Angelis. There are other advantages of not keeping live mice, he says. It has become very hard to ship live animals, particularly across borders. And there is the problem of 'gene drift' - the natural accumulation over generations of DNA variation as a result of background mutation. Another difficulty is that the characteristics making a particular mutant interesting can disappear.

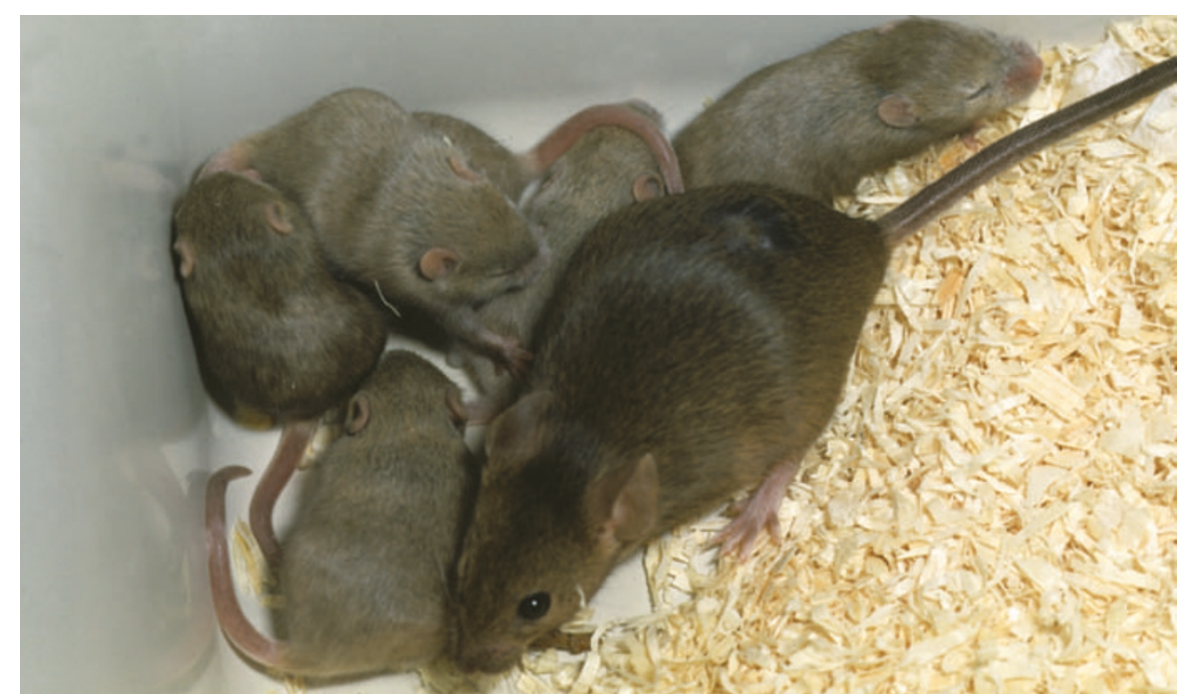

Pooled resources: a global network will soon make genetically modified mice readily available.

But for the moment, few labs can handle frozen embryos or sperm, so specialist repositories still do most of the 'reanimation', making the mice available as breeding pairs within three or four months. Archivists at the meeting noted that to exploit mouse mutant resources, many more labs should learn how to reanimate animals themselves.

\section{It's a knockout}

Geneticists around the world are pushing ahead with plans to scale up production of new mouse mutants for use as models of human disease (C. P. Austin et al. Nature Genet. 36, 921-924, 2004 and J. Auwerx et al. Nature Genet. 36, 925-927, 2004).

A US-based consortium is being spearheaded by Francis Collins, director of the National Human Genome Research Institute in Bethesda, Maryland, and former head of the international Human Genome Project. Its approach involves systematically knocking out mouse genes one by one in embryonic stem cells, which can later be used to make embryos.

This simple knockout technology is fast and cheap, but it has two disadvantages. Up to $15 \%$ of genes are needed for embryonic development, so any stem cell missing one of these will not develop into a mouse. And some knockout mice find ways to compensate for the lost function of the knocked-out gene and so appear normal.

Nevertheless, Collins estimates that stem cells covering most of the mouse genome will have been created within five years. He says that he is about to begin a worldwide e-mail survey to find out which knockout mice already exist, and to catalogue those available to researchers. He will then organize a workshop to discuss the implementation of the project.

Early next year, the US National Institutes of Health will call for proposals from scientists
Many medical researchers are not even aware that the mutant archives exist and can offer them useful models - while those who do know about them often fail to offer the archives new mutants they have created. The archivists pledged to organize themselves into a global network committed to educating researchers and sharing resources.

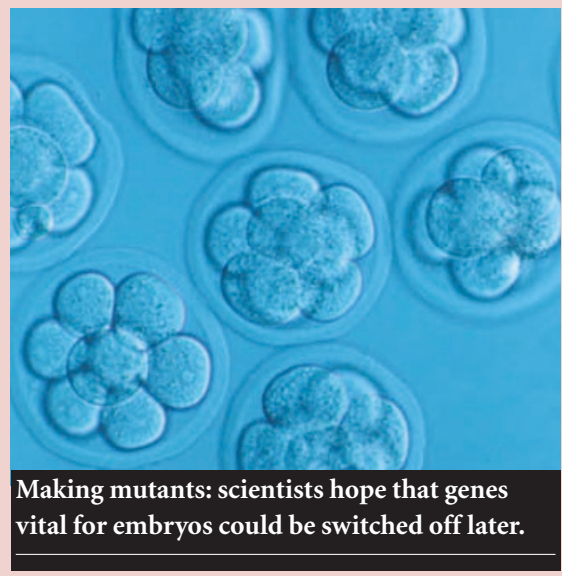

interested in participating. "Money will be tight I've just seen my budget figures - but the scientific need is compelling," Collins says.

A European-based consortium will focus on knockout embryonic stem cells containing genes that the experimenter will be able to switch on or off at will in the mutant mouse. A gene required for embryo development, for example, could be switched off only after birth, or a gene associated with a disease of old age could be switched on only in ageing mice. But this approach will be much more time-consuming and expensive than the US strategy. The consortium is nonetheless seeking support from the European Commission and hopes to start work next year. 